\title{
A MISSÃO "PEDRO FERREIRA DE OLIVEIRA"
}

\author{
UACURY RIBEIRO DE ASSIS BASTOS
}

As relacōes diplomáticas entre o Brasil e a Repúbllca do Paragual iniclaram-se na terceira década do século XIX, época em que a Secretaria para os Negócios Estrangeiros envia um representante, Manuel Correla da Camara, para Assuncão.

A atitude do Governo Imperial, tentando estabelecer relacōes diplomáticas com a vizinha República, constitul nitida definicăo da politica externa do Brasil, no que se refere à tragmentacão do antigo Vice-Reinado do Prata. Firma-se, pois, com Correla da Camara, a posiçăo braslleira favorável à constituicăo de paises independentes orlundos de antigas unidades administrativas do vice-reinado criado em 1776. Outra finalldade desta missăo é o uso do rio Paraguai por embarcacóes braslleiras.

Correla da Camara, ao solleitar de Francla autorlzacăo para navegar de Itapua até Colmbra, visava, sem dúvida, criar um precedente vantajoso para seu pais (1). A recusa do Presidente Perpétuo do Paragual é taxativa e as relacōes entre Francla e a diplomacia brasileira sāo, posteriormente, interrompldas de maneira drástica.

pistes dols objetivos tornam-se marcantes na Missāo Pimenta Bueno. Nas instrucōes entregues pela Secretaria de Estado para os Negócios Estrangeiros ao diplomata brasileiro que segula para Assunç̄o, os dols aspectos sāo recomendados com insistêncla. O Ministro Plenipotenclário do Brasil deve "empregar todos os melos que a sua habllidade the sugerir para evitar que o Paragual passe a fazer parte da Confederacão Argentina, e para neutralizar e diminulr a influencia de Rosas na Banda Oriental" (2). Refere-se ao uso do rio nos seguintes termos: "Destas breves consideracōes já se ve quanto são importantes para o Império as relacōes de amizade com o Paragual, a fim de prepará-lo para fazer-nos concessōes e celebrar conosco em larga escala convencōes, pelas quals possamos tirar, da inteira e ampla navegacăo daqueles rios, tơdas as vantagens que nos promete" (3).

(1) esi porém o soberano conceder-me a graça de fretar uma embarcacão que me leve ao Forte de Coimbra...> - Col. Visconde do Rlo Branco, n.o 642, do Catálogo I-29, 26, 10.

(2) A Missão Pimenta Bueno (1848-1847). Documentos, Ministérío das Relacóes Exteriores, 1966, p. 6.

(3) Idem, p. 4. 
Pimenta Bueno permanece alguns anos no Paragual, goza da conflanca de Carlos Antonio Lopes e participa como um dos principals colaboradores do perídico El Paraguayo Independiente. Este, caracterizava-se por oposiçăo tenaz contra Rosas e pela defesa sistemática do principlo da livre navegaç̄o dos rios. Nenhum diplomata brasilelro teve tanto prestigio junto ao Governo paragualo como o professor da Faculdade de Direito de São Paulo. Firmou tratado com Carlos António Lopes, em 1844, no qual o transito do rio é concedido para embarcacőes brasileiras. No artigo 35.0 ficou estabelecido que as questōes de limites serlam resolvidas tomando por base o tratado de 1777 . Contrariou, desta forma, as instruçóes que orlentavam suas atividades diplomáticas, e por esta razão o Impérlo recusou-se a
ratiflcá-1o. (4)

Firmou-se, desde então, o ponto de vista paragualo de vincular a solucão do problema da navegacão ao da questão de limites.

Após a queda de Rosas, o rio Paraná é aberto a tôdas as nacóes do mundo. - Paragual é um dos paises beneficlados e firma tratados com estados europeus, permitindo-lhes penetrar com suas embarcacōes até Assunçăo (5).

A obstinacăo paraguala, negando aquele direito ao Brasil, cria um impasse nas relacōes entre os dois paises. Perelra Leal, representante diplomático do Brasil em Assuncão, ê acusado de ridicularizar o presidente Lopes e convidado a abandonar o pais (6). Agrava-se, de manelra irreversivel, as relacoes entre os dols estados. o Visconde do Rlo Branco assim relata a resposta brasilelra: .... segulu-se a misstio especlal conflada ao chefe da esquadra Pedro Ferreira, que se apresentou nas Três Bocas, com uma imponente forca naval e tropas de desembarque. Essa missāo tinha por fim obter satisfacáo da ofensa felta ao Impérlo na pessoa do seu representante, e o reconhecimento do nosso direito de livre transito pelo rlo Paragual, quando nño iosse possivel chegar a um ajuste satisfatório sobre tódas as questóes. Chegando as. Tres Bocas a nossa esquadra, Carlos Lopes féz anunciar que estava pronto para uma negociacăo paciflca, mas que se lhe evitasse a presenca de uma forca estrangelra, que tornaria impossivel qualquer acordo amigável. Pedro Ferrelra, Infellzmente, conflou demaslado nessas declaracōes, e sublu só até Assuncuăo, contentando-se com um tratado de navegacão e comércio que seria aceito se pudesse ter logo execucăo, mas por uma cláusula ficava dependente do ajuste de limites" (7).

A sintese felta por José Maria da Silva Paranhos, leva-nos a Imaginar uma espécle de 10 gro no qual tería sido envolvido o comandante da esquadra. Como Secretárlo da Marinha, Paranhos fol um dos responsáveis pelo envio da esquadra. A sua observaçáo é em defesa própria, e do Gabinete ao qual pertencla.

A documentacão pertencente ao Arquivo Histórico do Itamarati, sob a denominacŭo "Missāo Pedro Ferrelra de Oliveira", e a leltura por nós realizada nos fornais argentinos e urugualos que na época abordaram o problema, permitiram-nos interpretacão bem diferente daquela que transcrevemos acima. Nos documentos examinados faltam "As Instrucōes" que deviam ser seguidas pelo representante brasileiro; mas existem várias referencias feltas a elas em oficios de Pedro Ferreira de Ollveira ao Secretário de Estado para os Negócios Estrangeiros, que nos permitem perceber a ambiguldade caracteristlica das determinacōes estabelecidas pelo Governo

(4) Idem, p. 9: eNestes têrmus convém que V. Mec procure negociar um tratado de limites sem o fundar no uti possidetis, nem tão pouco no tratado de $1777 \mathrm{~s}$.

(5) Tratados de navegacion suscritos entre el Paraguay y paises de America... - Asuncion, Imprenta Naval, 1960.

(6) Col. Visconde do Rio Branco, n.o 351 do Catálogo, I-29, 29, 24; n.० 20.

(7) Schenelder, L. - A guerra da Triplice Allanca. Nota de pé de página, p. 157. Edlcōes Cultura, S. Paulo, 1945. 
Imperial. A esquadra deveria penetrar até Assuncăo, exı̇gir as reparacōes morals e obter um tratado de navegacão. Tudo deveria ser feito para evitar um desenlace bélico. O chefe da esquadra, em reflexōes anexas às "Instrucōes", manifesta dúvidas: "... năo me parece bastante claro o número das instrucōes que diz: só no caso de que a pressuposta oposição possa ser levada a efelto por melo da forca deverá V.S. sobrestar no prosseguimento da expedicäo..." (8).

Qual a organizaç̄o da esquadra e as repercussōes que teve no río da Prata? Tais são os aspectos cuja análise torna-se imperiosa para compreender os motivos que levaram o representante brasileiro a "confiar demasiado nas declaracóes de Lopes".

A primeira noticia dada pelo jornal Comercio del Plata, de Montevideu, ainda que não condene a posicão braslleira, manifesta certa apreensāo pelos rumos que poderiam tomar os acontecimentos e pleitela a interferencla mediadora de Buenos Aires e da Confederacão "... na desagradável complicacāo em que se acham empenhados o Paragual e o Brasil..." (9).

De Montevidéu surgem as primeiras noticlas sôbre a constituicão da esquadra, seu poder de fogo, suas tropas de desembarque.

La Tribuna, publicada em Buenos Aires, noticla a presenca de uma esquadra de vinte barcos, 130 pecas de artilharia e 2.071 homens (10).

Se compararmos com a fơrca naval tranco-inglessa, formada por 12 a 15 barcos, que, vencendo a batalha de Obligado, rompeu o bloquelo estabelecido por Rosas, somos obrigados a reconhecer a importancia das forcas enviadas pelo Brasil. (11)

Além da Tribuna, cuja posicão é mals pró Brasil do que contra, outro fornal editado em Buenos Aires é o Nacional, que possui como redator Bartolomeu Mitre. Deste orgāo de imprensa partem as mals nitidas oposicōes à politica braslleira. - Nacional de 20 de janeiro de 1855, após qualificar o Impérlo como a Rússia da América, prossegue dizendo: "A politica expansionista do Brasil prossegue sem interrupcão. Os planos de Carlota Joaquina sāo retomados pelo Imperador. A diplomacia brasileira é paciente, recua, avanca de acôrdo com as circunstancias momentâneas, trabalha como uma aranha e, se não nos precavermos, logo seremos envolvidos por suas telas". O articulista condena Pereira Leal, acusando-o de contrabandista e irreverente em relaçăo ao govêrno paraguaio. Afirma que o desentendimento fol preparado e procurado pelo diplomata brasileiro. Quanto à questāo de límites entre Brasil e Paraguai, solidariza-se com este pais e afirma que "o predominio brasileiro no alto Paraguai, se forem obtidos os limites que pretende o Brasil, equivale a tornar-se dono de nossos rios".

O Nacional de 24 de janelro afirma: "O Brasil, a manelra de um herdeiro universal de tôdas as repúblicas limitrofes, propende, hoje, à absorçāo dos territórilos vizinhos, com o mesmo afinco com que os seus ascendentes, os portugueses, anexavam territórios da Coroa de Castela" (11).

- noticlário sôbre os preparativos bélicos que se faziam no Paragual para repelir a esquadra brasilelra é alarmante. A Tribuna ( 22 de janelro), baseada em informaçōes orlundas de Corrientes, noticla a mobllizacāo de 20.000 homens para

(8) A Missāo Pedro Ferreira de Oliveira (Arquivo Histórico do Itamarati) - Reflexōes sôbre as instrucōes anexas. (10-12-1854)

(9) «Comerclo del Platas, Sabado, 6 de Enero de 1855. Afio X, n.o 2652.

(10) «La Tribunas, 27-1-1855.

(11) Cady, John F. - La Intervencion extranjera en el Rio de la Plata, p. 173, Buenos Alres, 1943. 
a defesa do Paraguai. Na fronteira estavam concentrados 8.000 e 12.000 ao longo do rlo (12).

A frota braslleira deveria, caso houvesse desenlace bélico, receber apolo de tropas concentradas na frontelra do Rlo Grande do Sul e de contingente localizado no forte de Colmbra, sob o comando de Leverger.

Carlos Antonlo Lopes, através de proclamacăo dirigida ao exército, admite a possiblildade de desenlace bélico. Publicada a 21 de fevereiro no semandrio (periódico de Assuncáo), é transcrita no Comercio del Plata de 20 de marco. (13)

\section{Proclamacão}

"Vlva a República do Paragual

Do Presidente da Repúbllca ao Exército Soldados

Quando o chefe supremo da Repúbilica contava com uma paz segura, baseada nas relacōes amigávels com todos os vizinhos, ataca-nos e invade nosso territórlo um inimigo insidioso, o Brasil, cujo Imperador acabava de assegurar-nos uma paz inalterável em sua mensagem às camaras, invade nossos rios e nossa terra, e pretende impor-nos sua autoridade e suas ordens.

Uma esquadra brasllelra entrou no rio Paragual, sem que seu Governo nem seu chefe tenham enviado ao Governo da Republica um simples aviso; um ato que nāo tem exemplo a năo ser entre os selvagens. Chama-nos ao combate. Soldados, vamos lutar, porque obriga-nos a isso um Governo que, falando de paz e amizade, oferece-nos a guerra e seus males.

Soldados, a Pátria conta com seus filhos, conta com esse valor frio, com essa serenidade Imperturbável, que os faz arrostar os perigos e a morte, quantas vezes for pedido vosso auxilio.

Soldados! Seja qual for a sorte que a Providencla nos reserve, vossa resisténcla será um protesto eterno contra a injustica do Brasil e uma glória impereclvel, ainda que sejamos derrotados.

Soldados! Vlva a República! Independencia ou morte! seja nossa divisa. Sustente essa divisa e o Paragual far-se-á memorável e admirável."

Além da preparacāo psicológlca das tropas e de sua distribuiçăo em áreas estratéglcas, Pedro Ferrelra defronta-se com outros problemas: a existêncla de barcacas (14) carregadas de pedras que seriam lancadas no leito do rio, caso houvesse tentativa de penetracão nas aguas paragualas, e o reforco de fortalezas situadas em pontos estratégleos (Humaitá e Curupaiti) (15).

(12) «Di Nacionals, 25-1-1855: «Bi imperio del Brasil su tendencia a la expansion. P. Huergo.s

(13) A proclamacăo fol também publicada em jornais de Buenos Aires e da Confederaçáo.

(14) eLa Tribunas, 4-4-1855: ePouco antes da esquadra chegar à Assuncão o rio petrificou-se...s

Oflicio de Pedro Ferreira de Oliveira ao Visconde de Abaeté, 25-4-1855: sDemals havia no porto da capital grandes caixóes denominados piraguas, destinados a entupir o canal, cheios de pedra e metidos a pique.s

(15) Oficlo de Pedro Ferreira a Visconde de Abaete, 25-4-1855. Referindo-se às baterias de humaitá: cConforme tôdas as noticias estavam colocadas em posiçăo vantajosa e guarnecidas por sessenta pecas de artillharia. 
Estacada posta numa curva do rio Paragual obrigava qualquer embarcacăo que tentasse passar frente a Tacumbu seguir por uma rota que a tornava fácll alvo da fuzlaria assentada na fortaleza, ao mesmo tempo que impossibilitava o revide (16).

Os officios de Pedro Ferrelra, enviados à Secretaria de Negóclos Estrangeiros, săo otimistas até o instante em que récebe intimaçăo para ancorar a esquadra sob seu comando fora das águas paragualas. Após declarar sua finalidade paciffea e diplomática, autorizado a dirigir-se para a capital do pais com uma unica embarcacão.

A demonstracăo de fôrç năo intimidou Assuncão, e as negociacóes se efetuaram em clima desfavorável ao Brasil. Vários autores têm responsabllizado Pedro Ferrelra pelo tracasso de sua missāo, caracterizada pelo duplo aspecto: belicoso e diplomático.

- Paragual soube tirar proveito das repercussōes que a ameaca naval representava, e o comandante da esquadra brasileira achou melhor contornar a situacăo.

A existência de um plano bélico do Brasil é evidenciada pelo poderio da esquadra. Suas linhas gerals săo especificadas em officlo dirigido pelo comandante da esquadra, que se encontrava em villa Oliva, a Francisco Manuel Barroso.

Temendo uma traicăo, estabelece um roteiro, que deveria ser seguido caso se concretizaisse o atentado a sua pessoa. As ordens enviadas sáo as seguintes:

1) envio de parte da esquadra até Coimbra, para que se estabelecesse a unĭ̄o com as tropas sob comando de Leverger;

2) envio de mensageiro ao Presidente da Provincla do Rlo Grande do Sul e ao comandante da fronteira de Urugualana;

3) rompimento das hostilidades sobre todas as margens do rio, com aprisionamento das embarcaçēes que fossem encontradas sob a bandeira paraguafa (17).

A presença do governador de Mato Grosso em Colmbra é comentada pelo Visconde de Taunay (18).

A concentracăo de tropas na fronteira do território das Missōes é confirmada por Paranhos (19).

O plano não poderia ter surgido em aguas do Paragual. A presenca de tropas brasileiras em pontos estratégicos indica uma preparaç̌o prévia e ressalta a contribulcăo do Gablnete Imperial no esquema que é encaminhado por oflclo ao capltāo de mar e guerra, Francisco Manuel Barroso.

(16) Idem: ๔As baterias Tacumbu năo poderiam ser atacadas pelos navios grandes, que nāo poderiam chegar a conveniente distancla e que pelo contrário flcariam muitas léguas abaixo. Também nāo poderiam ser atacadas pelos navios pequenos, porque estāo a uma altura de mals de 60 pés, e o canal único que existe é encostado a barranca; além do que o govérno do Paragual tinha felto construir duas estacadas com vigas fortes interceptando a passagem e obrigando os barcos a navegar encostados a barranca. Em uma tal posicăo a artilharla do navio náo pegar e da parate oposta a fuzilaria podia extinguir as guarnicōes sem receber mais dano.

(17) Oficlo de Pedro Ferreira a Francisco Manuel Barroso, 14-3-1855. Missäo P.F.O. - Arquivo Histórico do Itamarati. Os trés itens enumerados constam ueste oficio.

(18) Taunay, Alfredo d'Escragnolle (VIsconde de Taunay). Augusto Leverger, pp. 97-99, Melhoramentos S. Paulo 1931. Segundo o blógrafo de Leverger este permaneceu em Colmbra de 14 de 2 de 1855 até 15 de 11 de 1856.

(19) Veja-se a citacāo n.o 7 . 
- abandono da solucăo armada é estabelecldo sob forma definitiva quando Pedro Ferrelra dellbera seguir como diplomata, com um único barco. Justifica sua atitude perante o Gabinete Imperial, apresentando uma série de razōes: 1) a oposlcăo de certo órgāo da imprensa de Buenos Aires (o Nacional), no qual existlam pessoas Influentes junto ao governo (Mitre); 2) a ausêncla de Urquiza da capital da Confederacăo Argentina, quando da passagem da esquadra; 3) a Insistencia de seu ministro (Gutierrez) e do vice-presidente (Carril) para que a solucháo bélica cosse afastada em definitivo e adotado o debate diplomático (20).

Se a estes fatores acrescentarmos a moblilzacāo desencadeada por Carlos Antónito Lopes, compreenderemos os rumos seguldos e a deliberacão adotada por Pedro Ferreira, de contornar a situaçao. Escolhe a solucão diplomática, para a qual estava despreparado; prova disto é a sua resposta ao Plenipotencíario paraguaio, ao ser sugerldo o debate sob forma escrita. Francisco Solano Lopes argumenta a favor deste critério, com a necessidade de reunir comprovantes para que o Paragual não rosse acusado, diante do mundo llustrado, de dificultar o bom exito das negoclacōes por "motivos frivolos" (21). A resposta do representante brasileiro fol de que não estava "munldo de arquivos e alfarráblos velhos para sustentar uma polemica, talvez, puramente literárla" (22).

Nas conversacōes, a questăo de limites era a mals dellcada. O Brasil, baseado nos resultados dos demarcadores de 1750 , relvindicava a linha do Iguatemi e, como contra-vertente dêste, aceltava o Apa. Desta forma, o Igurei passava a ser o Iguateml, e o Corrlentes tornava-se Apa.

Azara, percebendo a imprecisāo dos textos dos tratados, havia defendido com veemencla a linha Ivinhelma-Mbotetey, baseando-se na denominacão de Jaguarel dada ao Ivinhelma. A diplomacla paraguala adota o ponto de vista de Azara.

A semelhanca entre as palavras Ygurel e Yaguarel fol o principal argumento do demarcador espanhol da segunda partida do Tratado de Santo IIdefonso (23).

As duas posic̄ōes, fundamentadas em interpretacōes dos tratados firmados pelas antigas Metrópoles, tornam-se irredutiveis. A solucão do problema da navegacão, vinculada a de limites, anula por completo os resultados atingidos para aquela primeira questāo.

A esquadra nāo intimidou o Paragual, e os paises intensifleam seus preparativos béllcos, rumo a uma soluçāo armada.

Ao concluir sua missão, Pedro Ferrelra comunica à Secretaria para os Negócios Estrangeiros: "A convlccāo em que estou, de que as questб̄es com Lopes só terminarāo por uma guerra, é que me induzlu a fazer a convencāo que adia os tratados de limites, e se observam as frontelras em statu quo, e insistindo para que ele mande a Córte do Impérlo um Plenipotenciário tratar, tive por vista o terminar as negoclacōes por forma que afinal o Governo Imperial possa no futuro deliberar como julgar conveniente" (24).

(20) Oflelo de Pedro Ferreira de 1-4-1855 ao Visconde de Abaeté. Missāo P.F.O. - Arquivo Histórico do Itamarati.

(22) Oflelo de Pedro Ferreira ao Visconde de Abaeté, 10-4-1855. Missāo P.F.O. - Arquivo Histórico do Itamarati.

(23) Calvo, Carlos - Coleccion completa de Tratados (Correspondencla de D. Fellx Azara), Tomo 4, pp. 5-53.

(24) Oflclo de Pedro Ferreira de Olveira ao Visconde de Abaeté. 25-4-1855. Mis-
săo P.F, O. 